\title{
APLIKASI ELEMEN PEMIKIRAN SAINTIFIK DALAM PENGAJIAN SYARIAH
}

\author{
Alias Azhar* \\ Rahimin Affandi Abdul Rahim**
}

\begin{abstract}
Perspective that considers the full value of knowledge is a kind of knowledge constructed by the human mind in the context of culture, education and social conception. In principle, the development of a strong education system requires the development of educational curricula and teaching and learning environment that meets the current needs. One of the important elements that should be included in that system is the application of scientific thinking. In the field of Shariah studies, this will be the catalyst for the birth of the knowledge that generates an optimal mind function. It will produce students who can think rationally, carefully and objectively which provide them a force of formula and analysis, so as to enhance the ability of ijtihad.
\end{abstract}

Keywords: Fiqh, scientific thinking, Shariah studies

* Lecturer, College of Law, Goverment and International Studies, Universiti Utara Malaysia.

** Associate Professor, Department of Fiqh and Usul, Academy of Islamic Studies, University Malaya. 


\section{PENDAHULUAN}

Penulis mendasarkan perbincangan dan membentuk kerangka teori berasaskan kepada cetusan pendapat sarjana kontemporari ${ }^{1}$ berhubung keperluan interaksi dan integrasi pengajian sains perubatan dan pengajian Syariah. Selain itu, beberapa idea bernas telah dibangkitkan oleh fuqaha semasa berkaitan perkembangan pengajian Syariah sebagai satu disiplin ilmu yang sentiasa bersifat dinamik, realistik serta sentiasa up-to-date. ${ }^{2}$ Kesinambungan itu, Mahmood Zuhdi Abdul Majid, turut mengembangkan idea ini dengan mengulas tentang perlunya pengajian Syariah ini mengalami perubahan dan pembaharuan disebabkan keperluan masyarakat yang berubah sejajar dengan perkembangan sains dan teknologi. ${ }^{3}$

Sebelum kelahiran ilmu sains dan teknologi itu sendiri, telah wujud ilmu falsafah ulung yang dipelopori oleh saintis muslim seperti al-Farabi dan Ibn Sina. Falsafah merupakan perkataan berasal daripada bahasa Yunani yang dipinjam oleh bahasa Arab. Terbentuk daripada dua kata kerja philo dan sophia. Philo bererti cinta dan sophia membawa makna hikmah atau kebijaksanaan. Oleh itu, philosophia atau falsafah bermakna cintakan hikmah atau cintakan kebijaksanaan. ${ }^{4}$ Malah rumusan makna falsafah secara umum ialah, ilmu yang istimewa sebagai berfungsi mencuba menjawab masalah yang tidak dapat dijawab oleh ilmu pengetahuan biasa, kerana masalah tersebut di luar jangkauan ilmu pengetahuan biasa. ${ }^{5}$

1 Muhammad Hashim Kamali (1996), "Protection Against Disease: A Syariah Perspective On AIDS", Law Journal, v. 5, no. 1 \& 2, Petaling Jaya: IIUM Press, h. 1.

2 Yusuf al-Qaradhawi (2000), Pembaharuan Fiqh Abad 21, Abu Mazaya al- Hafiz (terj. ) Kuala Lumpur: Al- Hidayah Publisher, h. 2.

3 Mahmood Zuhdi Abdul Majid (1992), Sejarah Pembinaan Hukum Islam, Kuala Lumpur: Universiti Malaya, h. 12.

4 Endang Saifuddin Anshari (1982), Sains, Falsafah dan Agama, Kuala Lumpur: Dewan Bahasa \& Pustaka, h.75.

$5 \quad$ Ibid., h. 81. 


\section{AKAL \& PEMIKIRAN: PERSPEKTIF FUNGSIONAL}

Akal merupakan bahagian terpenting dalam kehidupan manusia, justeru, ianya dikategori sebagai salah satu elemen yang perlu dipelihara termasuk agama, nyawa, maruah dan harta. Kelimalima elemen tersebut terkandung dalam visi dan misi syariat Islam. Wahyu sebagai sumber ilmu yang utama tidak menafikan sama sekali potensi fungsional akal. Al-Quran mengiktiraf kepentingan dan keperluan akal. Selain itu, menurut epistemologi Islam, akal dianggap sebagai sumber kedua selepas wahyu.

Menurut Edward De Bono, dalam merumuskan falsafah pemikiran tiga orang tokoh pemikir silam iaitu Socrates, Plato dan Aristotle, bahawa sistem pemikiran adalah berdasarkan kepada 4 elemen iaitu, pertama; analisis, kedua; penilaian, ketiga; hujah dan keempat; kritikan. ${ }^{6}$ Menurut beliau lagi, tahap pemikiran pula terbahagi kepada lima iaitu; ${ }^{7}$

1. Menunjukkan matlamat.

2. Menunjukkan maklumat.

3. Tahap kemungkinan.

4. Menapis, memeriksa dan memilih penyelesaian yang sesuai.

5. Menunjukkan langkah tindakan.

Selain itu, proses asas pemikiran pula terdiri lima langkah utama bermula dengan umum atau spesifik, kedua; unjuran, ketiga; mengarah perhatian, keempat pengiktirafan dan proses terakhir pergerakan. ${ }^{8}$ Gagasan ulung dan berotoriti Edward De Bono berkaitan pemikiran ialah,

"pembelajaran pemikiran harus dijadikan subjek penting dalam pembentukan kemahiran". ${ }^{9}$

Edward De Bono (2003), Belajar Berfikir, Anggota Persatuan Penerbit Malaysia (terj.), Kuala Lumpur: Golden Books Centre, h. 13.

Ibid., h. 22.

Ibid. , h. 29.

9 Edward De Bono (1993), Tactics: The Art Of Science Of Success, London: HarperCollinsPublishers, hh. 124-126. 
Sehubungan itu, terdapat dalam kalangan sarjana ${ }^{10}$ yang telah mengemukakan teori kepentingan mengetahui selok-belok berfikir sebagai satu kemahiran utama dalam kehidupan. Proses berfikir melibatkan interaksi antara pengetahuan, kemahiran kognitif dan sikap atau nilai dalam minda. Selain itu, terdapat beberapa jenis pemikiran seperti kritis, kreatif, konvergen, lateral, menegak, penaakulan dan sebagainya. ${ }^{11}$ Menurut sains otak, wujud dua hemisfera otak iaitu otak kanan atau hoka dan otak kiri atau hoki. ${ }^{12}$ Selanjutnya, teori ini telah mengklasifikasikan manusia kepada dua kelompok utama iaitu ${ }^{13}$, manusia yang hebat hokanya ialah terdiri daripada ahli-ahli seni dan kreativti, manakala yang kuat hokinya pula, terdiri daripada ahli sains dan teknologi. Secara tidak langsung, boleh difahami di sini, bahawa kemahiran berfikir manusia terbahagi kepada dua iaitu, sains dan sastera.

Aspek kecenderungan hoka dan hoki juga dianggap pasangan kepada intelek, yang terdiri daripada rasional (hoki) dan intuitif $(\text { hoka })^{14}$. Namun tidak dinafikan bahawa, kemahiran berfikir yang efektif dapat diaplikasi melalui adaptasi kedua-dua kecenderungan tersebut dalam proses membuat keputusan. Ini jelas dalam kaedah saintifik Islam elemen intuitif $^{15}$ diaplikasikan sebagai elemen pemikiran saintifik yang sangat besar makna simbolisnya. Dalam kajian sains, aspek berfikir juga akan membawa kepada pertimbangan intelek, ${ }^{16}$ kerana ahli sains bukan sahaja memberikan

$10 \quad$ Ibid., hh. 124-130. Lihat juga, Harun Yahya, (2003), Berfikir, Kuala Lumpur: Jasmin Enterprise, h. 14-17.

11 Mohd Nashuha Jamidin et al. (1996), Kemahiran Berfikir Dan Belajar, Selangor; Penerbit Fajar Bakti, hh. 5-6.

12 Osman Bakar (1994), "Persoalan Mengenai Kaedah Dalam Sains Islam", dalam Baharudin Ahmad (ed.) Falsafah Sains Daripada Perspektif Islam, Selangor: DBP, h. 91. Lihat juga, Mohd Amin Mohamad Sulaiman (2006), Membuat Keputusan: Panduan Aplikasi Harian, Kuala Lumpur: DBP., h. 38-42.

13 Mohd Yusof Hasan (2005), "Paradigma Pemikiran Dalam Epistemologi Melayu", dalam Hashim Musa (ed.), Bahasa \& Pemikiran Melayu, Kuala Lumpur: APMUM, h. 72.

14 Osman Bakar, (1994), op.cit.

15 Saintis Islam seperti Ibn Sina mempraktikkan kaedah ini dalam menyelesaikan masalah sains.

16 Abdul Latif Samian (1993), Pengenalan Sejarah Dan Falsafah Sains, Kuala Lumpur: DBP, h. 9. 
penjelasan tentang benda dan aktiviti yang dilakukan sematamata. Bahkan, turut menawarkan penerangan tentang kelakuan benda-benda tersebut.

Kemahiran berfikir mempunyai asas yang rapat dengan jenis dan cara belajar individu. Bagaimana proses pembelajaran dan tindakan banyak berkait rapat dengan cara berfikir. Begitu juga halnya, cara individu tertentu menanggapi sesuatu realiti, banyak dipengaruhi oleh pola pemikiran. Aplikasi elemen pemikiran yang komprehensif, memerlukan kepada strategi dan mekanisme berfikir yang konstruktif. Secara literalnya, proses berfikir melibatkan terma tindakbalas yang berlaku dalam mental manusia, turut melibatkan beberapa peringkat aktif seperti berikut ${ }^{17}$ :

i. mengenal dan memahami masalah.

ii. mencari maklumat sebagai penyelesaian.

iii. membuat penolakan setelah menimbangkan segala kemungkinan penyelesaian.

iv. menilai hipotesis yang dibuat.

v. membuat keputusan.

\section{PEMIKIRAN SAINTIFIK: SATU PENGENALAN}

Pemikiran saintifik dalam fokus perbincangan ini, adalah menjurus kepada strategi dan mekanisme berfikir yang diaplikasikan dalam kaedah saintifik. Secara umumnya, mekanisme pemikiran saintifik adalah bermatlamatkan memperolehi ilmu pengetahuan. Rasionalnya, sebahagian besar ilmu pengetahuan daripada semua bidang ilmu, adalah terhasil daripada penyelidikan ahli-ahli ilmu dalam bidang berkaitan. Namun begitu, sesuatu penyelidikan itu perlu dilaksanakan dengan mengaplikasikan kaedah berfikir yang saintifik sifatnya. Natijah ilmunya, barulah boleh dianggap sebagai satu sumbangan yang baru dan bermanfaat kepada bidang ilmu berkenaan.

Sesuatu yang pasti ialah "saintifik" memang berasal daripada "sains".Namun, dalamperbincangandisini,penulistidakmeluaskan

17 Shahabudin Hashim et al. (2003), Pedagogi: Strategi Dan Teknik Mengajar Dengan Berkesan, Kuala Lumpur: PTS Publication, h. 75. 
skop sains dengan maksud ilmu pengetahuan atau penggunaan ilmu pengetahuan yang berkait dengan alam kebendaan. ${ }^{18}$ Perkara yang menjadi fokus di sini, ialah elemen pemikiran yang digarapkan dalam penyelidikan sains bagi menerangkan fenomena-fenomena melalui pendekatan yang dinamakan kaedah saintifik. Secara holistiknya, kaedah ini bergantung kepada logik penaakulan akal manusia dan berdasarkan fakta yang munasabah menurut perspektif pemikiran manusia. Selain itu juga, sesuatu prinsip yang dihasilkan oleh sains mestilah boleh diuji secara empirik.

Justeru, setiap hasil kajian atau penemuan boleh diulang kaji oleh sarjana lain yang menggunakan kaedah yang sama. Lantaran itu, setiap penyelidik perlu menerangkan secara terperinci tentang kaedah yang digunakan, tanpa menyembunyikan sesuatu. Resolusi awalan yang boleh dibuat, bahawa sains adalah proses mengumpul fakta, mengklasifikasikannya dan menegakkan fakta. Aspek yang lain pula, fakta sains bersifat tidak mutlak, sebagaimana difahami tentang takrif fakta yang sebenar, iaitu, tidak boleh dipertikaikan lagi atau sesuatu yang tidak boleh berubah. ${ }^{19}$ Hakikatnya, fakta sains adalah bersifat relatif dan mengalami perubahan. Malah fakta dalam konteks sains, hanya terhad dalam perspektif ilmiah semata-mata. ${ }^{20}$

Secara praktisnya, kepentingan utama yang menjadi rujukan penulis ialah, usaha saintifik adalah bertujuan mengetahui (apakah) dan memahami (bagaimanakah dan mengapakah). Elemen pemikiran saintifik yang mendasari kajian juga, adalah bebas daripada keterikatan perbincangan falsafah sains itu sendiri. Penulis tidak menafikan hubungan yang wujud antara falsafah dan sains. Sebagaimana pandangan Baharudin Ahmad yang menyatakan bahawa, sains dan teknologi hanya akan wujud apabila falsafah sains itu jelas dapat dikemukakan. ${ }^{21}$ Namun, justifikasi daripada kenyataan beliau, lebih merujuk kepada agenda islamisasi sains.

18 Ahmad Mahzan Ayob (1997), Kaedah Penyelidikan Sosioekonomi, ed. 2, Kuala Lumpur: DBP., h. 6.

19 Ibid., h. 7.

20 Sidek Mohd Noah (2002), Rekabentuk Penyelidikan: Falsafah, Teori Dan Praktis, Serdang: UPM, h. 3

21 Baharudin Ahmad (1994), op.cit., h. xiv. 
Falsafah antara lainnya, bertujuan untuk menjelaskan lagi kepada kita berkaitan perkara yang difikirkan. ${ }^{22}$ Manakala pemikiran pula, tidak dapat disamakan dengan mengetahui, kerana kita hanya akan mengetahui selepas berfikir. ${ }^{23}$ Bahkan, berfikir itu, adalah proses untuk mengetahui. Bagaimana pun, pengertian falsafah secara popularnya ialah berfikir. Hakikatnya, jika kita hanya berfikir sahaja, tidak semestinya kita boleh telah dikategorikan sebagai berfalsafah. Malah menurut Abdul Rahman Abdullah, berfikir secara falsafah seharusnya mengandungi ciriciri seperti berikut ${ }^{24}$ :

1. Berfikir secara radikal, iaitu secara mendalam hingga ke akar umbinya atau asal-usulnya dan hakikatnya.

2. Berfikir secara universal, iaitu menurut pengalaman manusia umumnya, bukannya secara khusus dan terbatas.

3. Berfikir secara integral, iaitu berpadu secara lengkap pada masing-masing bahagiannya.

Berdasarkan ciri-ciri ini, kita lihat falsafah daripada perspektif sejarah perkembangannya telah dianggap sebagai induk ilmu pengetahuan seluruhnya. Falsafah juga telah melahirkan cabangcabang ilmu pengetahuan lain. Antaranya matematik, perubatan, kimia, fizik dan sebagainya, yang terkandung dalam kurikulum pengajian sains, begitu juga kurikulum pengajian Islam. ${ }^{25}$ Selain itu juga, menurut Abdul Latif Samian, ${ }^{26}$ pemikiran saintifik tidak terpisah daripada falsafah. Malah menurut beliau lagi, aspek terpenting yang wujud dalam hubungan antara kedua-duanya ialah, pemikiran menjadi isu fundemental dalam konteks menentukan saintifik atau tidak sesuatu bidang ilmu itu.

Kebolehan berfikir amat bergantung kepada pengetahuan dan pengalaman seseorang. Ringkasnya, lebih banyak pengetahuan dan

Abdul Latif Samian (1993), op.cit., h. 2.

23 Osman Bakar (1993), Islam Dan Pemikiran Sains Masa Kini, Kuala Lumpur: Mekar Publisher \& ASASI, hh. 1-3.

24 Abdul Rahman Abdullah (2003), Apa Itu Sains?, Kuala Lumpur: PTS Publications, h. 1.

25 Ibid.

26 Huraian lanjut dalam, Abdul Latif Samian (2003), Perkembangan Sains Dan Peradaban Manusia, Bangi: UKM., h. 128. 
pengalaman yang ada pada diri seseorang, lebih besar kemungkinan untuknya berfikir dan memberi cadangan penyelesaian yang membina. Namun dalam aplikasi kaedah saintifik, selain bersifat objektif bukan subjektif, ianya juga bercirikan bebas daripada pertimbangan nilai. Jelas di sini, bahawa penyelidikan saintifik tidak boleh dipengaruhi oleh unsur-unsur nilai luaran, seperti latar belakang pendidikan, keluarga, rakan sebaya, persekitaran sosial dan sebagainya. ${ }^{27}$ Rasionalitinya, ialah bagi mengelakkan berlaku bias dan prejudis dalam penyelidikan yang akan memberi kesan kepada hasil penyelidikan.

Kriteria kaedah saintifik turut membuktikan bahawa masyarakat berhak menilai danmengawal aspek aktiviti penyelidik. Terkandung dua ciri utama bagi semua bidang penyelidikan saintifik iaitu:28 (1) darjah kawalan yang dikenakan sesuatu penyelidikan itu, dan (2) kawalan itu perlu terbuka kepada orang ramai untuk memeriksanya. Bagi ciri kedua, membawa erti besar kepada persoalan kredibiliti dan integriti penyelidik. Justeru, difahami bahawa sesuatu karya berteraskan penyelidikan saintifik boleh dinilai dan diperiksa oleh masyarakat. Para penyelidik tidak boleh menyembunyikan fakta atau metodologi kajian yang digunakan.

Kajian ini telah menemui aspek umum berkaitan perbezaan yang wujud antara sains Islam dan Barat. ${ }^{29}$ Namun seperti yang ditekankan dalam kajian ini ialah, titik persamaan yang wujud antara kedua-duanya. Aspek perbezaan adalah meliputi tiga perkara iaitu, aspek falsafah, metodologi dan konseptual. Perbezaan ini hampir tidak dapat dipastikan jika tiada pendedahan tentang historikal sains yang menjelaskan tentang epistemologi berbeza antara sains Islam dan Barat.

Perkara ini harus difokuskan, agar dapat menafikan spekulatif negatifberhubung dengan apayangbakal dibincangkan selanjutnya. Dua konotasi negatif telah timbul dalam rangka usaha menafikan sumbangan bermakna para saintis muslim dalam usaha Islamisasi sains. ${ }^{30}$ Pertamanya, dilabelkan sebagai aliran saintisme Islam,

\footnotetext{
27 Lihat Sidek Mohd Noah (2003), op. cit. h 5.

28 Ahmad Mahzan Ayob (1997), op. cit., h. 11.

29 Ziauddin Sardar (1992), Hujah Sains Islam, (terj. ) Abdul Latif Samian, Kuala Lumpur: DBP.

30 Abdul Rahman Abdullah (2003), op. cit, h. 139.
} 
yang bermaksud kekaguman berlebihan terhadap kemajuan sains dengan kaedah-kaedah saintifik. Kedua, aliran akomodasionisme, sebagai usaha menyesuaikan atau menyelaraskan ajaran-ajaran agama yang bersifat tetap dengan prinsip-prinsip sains moden yang berubah-ubah.

Pemikiran saintifik merupakan satu kemahiran untuk berfikir mengenai alam dan fenomenanya mengikut satu set kaedah dan metodologi yang spesifik. Kaedah-kaedah yang spesifik termasuklah; ${ }^{31}$

a) Persoalan yang dikaji

b) Teori dan konsep yang berkaitan

c) Merangka dan menguji hipotesis

d) Merekabentuk eksperimen atau kajian

e) Memahami apa yang dicerapkan dalam eksperimen

f) Membuat inferens dari hasil kajian

g) Mengaitkan data dengan teori yang mendasari kajian

h) Membuat kesimpulan.

Di sini terkandungnya kaedah berfikir secara induksi, deduksi, logik, analogi, kreatif dan menggunakan statistik dalam setiap langkah yang diaplikasi dalam pemikiran saintifik. ${ }^{32}$

Merujuk khusus kepada kaedah berfikir secara logik atau boleh diertikan sebagai kaedah mantik, amat berperanan sebagai mekanisme pemikiran yang sah bersama-sama dengan fakta atau bukti yang disahbenarkan. ${ }^{33}$ Untuk memastikan kebenaran dan memahami persoalan kajian dengan lebih mendalam, kaedah deduktif dan induktif ${ }^{4}$ turut diadaptasikan secara efektif. Deduktif ialah membuat kesimpulan daripada maklumat umum kepada khusus. Ia adalah satu proses membuat kesimpulan dengan berfikir secara logik. Melalui proses deduktif kesimpulan atau

31 Abdul Latif Samian \& Khairul Anwar Mastor (2003), op. cit., h. 127. Ainon Mohd \& Abdullah Hassan (2003), Belajar Berfikir, Pahang: PTS Publications \& Distributor, hh. 227- 246.

32 Chua Yan Piaw (2004), Creative And Critical Thinking Styles, Serdang: UPM, hh. 23-25.

33 Abdul Latif Samian (2003), op.cit., h. 108.

34 Sidek Mohd Noah (2002), op. cit., hh. 5-6. 
rumusan dibuat daripada maklumat dan fakta yang ada. Oleh yang demikian, deduktif dapat dirumuskan sebagai proses mental membuat kesimpulan daripada keadaan yang umum kepada yang khusus. Induktif pula ialah proses membuat kesimpulan daripada khusus kepada umum. Ia adalah cara takulan yang mendapat hukum umum dari hal yang tertentu.

Kaedah logik sebagai elemen pemikiran saintifik turut mendapat maklumbalas dan reaksi berbeza daripada kalangan sarjana berhubung keserasian agama dan sains dalam konteks aplikasi logik. Ahmad Mahzan berpendapat, ${ }^{35}$ kaedah pemikiran logik mencetus kontradikisi jelas antara agama dan sains. Persepsi akademik beliau, bahawa aplikasi logik tidak releven dalam konteks akidah. Namun respon berbeza diberikan oleh sarjanasarjana pemikiran Islam lain, ${ }^{36}$ begitu juga, penulis melihat elemen pemikiran logik amat realistik dan praktik dalam pemikiran fiqh ${ }^{37}$ bagi mengukuhkan instrumen tafaqquh. Sehubungan itu, teknik penyelesaian masalah berasaskan pemikiran logik meliputi tiga langkah utama iaitu ${ }^{38}$ : pertama; mendefinisikan masalah, kedua; mengkategorikan masalah, dan ketiga; alternatif penyelesaian.

Pemikiran logik amat memerlukan garapan bersama dengan pemikiran kritis dan kreatif. Kedua-dua kemahiran berfikir ini, merupakan asas terpenting dalam usaha mencapai keabsahan dan kebolehpercayaan teori atau keputusan berdasarkan logik. Kritis dan kreatif mampu mendorong individu untuk menguji kebenaran sesuatu perkara atau masalah agar tidak membentuk kesimpulan yang salah. Di samping itu, ia dapat membentuk keupayaan memproses maklumat dan menghasilkan sesuatu yang baru. ${ }^{39}$ Dalam konteks yang lebih luas, kritis dan kreatif boleh digunakan

35 Ahmad Mahzan Ayob (1997), op. cit., h. 10-11.

36 Muhammad Zainiy Uthman (2004), Logik Dan Analisa Ilmiah Dalam Pemikiran Islam, dlm. Mohd Fauzi Hamat et al. (eds.) Pemikiran Islam Dan Cabaran Semasa, Kuala Lumpur: APIUM.

37 Merujuk kepada teori Maqāșid al-Syarīah dalam usaha menentukan status maṣlahah \& mafsadah, darūriyyāt al-khams dan begitu juga fiqh al-aulawiyyāt.

38 Mohd Nashuha Jamidin (1996), op. cit., hh. 86-87.

39 Poh Swee Hiang (1997), Kemahiran Kritis Dan Kreatif, Kuala Lumpur: Kumpulan Budiman, h. 13; lihat juga, Mohd Michael Abdullah (1995), Pemikiran Kritis, Kuala Lumpur: DBP, hh. 2-3. 
secara optima dalam proses menyelesaikan masalah atau membuat keputusan. Kedua-dua elemen pemikiran ini mempunyai fungsi yang berbeza, namun dalam aplikasi saintifik kedua-duanya boleh digabungkan serentak bagi memperolehi hasil yang jitu. Jadual 1 di bawah menunjukkan fungsi pemikiran kritis dan kreatif dalam aplikasi penyelidikan saintifik ${ }^{40}$ :

\section{Jadual 1: Fungsi \& Perbezaan Pemikiran Kritis Dan Kreatif}

Pemikiran Kritis

Mencirikan

Membandingkan dan membezakan

Mengumpul dan mengelaskan

Membuat urutan

Menyusun ikut keutamaan

Menganalisis

Menilai

Membuat kesimpulan
Pemikiran Kreatif

Menjana idea

Membuat inferens

Menghubungkaitkan

Membuat hipotesis

Mengitlak

Menganalogi

Membuat gambaran mental

Mereka cipta

Elemen pemikiran saintifik seperti analogi atau diistilah dalam pengajian Syariah sebagai al-qiyās, adalah penting dalam kaedah pengajaran terutamanya apabila konsep yang disampaikan ialah berasaskan teori yang rumit. Analogi seperti pentakrifan Abdul Latif Samian, ialah satu proses meminjam konsep atau idea yang sedia ada dalam memahami fenomena atau situasi yang baru. Proses analogi turut menggunakan kaedah abduksi, dan ianya terdiri daripada objek, peristiwa situasi yang berkongsi kesamaan ciri atau pola dari segi aspek-aspek luaran atau mekanisme. ${ }^{41}$ Selain itu, penggunaan kaedah analogi ini lebih penting dalam pemikiran saintifik untuk memahami konsep, mekanisme atau menerbitkan inference bagi menyelesaikan masalah baru dan membina konsepkonsep atau hukum-hukum umum ${ }^{42}$. Konklusinya, mencipta analogi ialah membentuk kefahaman tentang suatu konsep secara

40 Muhd Nashuha Jamidin et al. (1996), Kemahiran Berfikir Dan Belajar, Kuala Lumpur: Penerbit Fajar Bakti, h. 7.

${ }^{41}$ Abdul Latif Samian, (2003), op. cit., h. 102-103.

42 Ibid. 
mengaitkan konsep itu dengan konsep lain yang mempunyai ciri yang serupa. Kemahiran ini juga digunakan untuk memahami konsep yang abstrak.

Membentuk analogi memerlukan strategi terancang untuk memastikan analogi yang dibuat bertepatan dan munasabah. Berikut adalah langkah-langkah yang harus diikuti dalam strategi membina analogi ${ }^{43}$ :

1. Kenalpasti apakah persamaan-persamaan yang terdapat pada objek atau idea yang cuba kita fahami.

2. Pastikan persamaan yang dibuat adalah signifikan atau bermakna.

3. Kenalpasti perkara yang kita tahu tentang objek pertama, tetapi kita tidak tahu tentang objek kedua atau lainnya.

4. Perhatikan sama ada terdapat perbezaan di antara keduadua objek atau idea yang boleh memberi kesan terhadap perkara yang cuba kita fahami.

5. Kesimpulan apakah yang boleh kita buat berdasarkan perkara yang cuba kita fahami melalui analogi yang kita buat.

Kelebihan fungsional elemen pemikiran dan kaedah saintifik adalah tertakluk kepada strategi aplikasinya. Sejauhmana strategi dibuat dan dilaksanakan secara sistematik, merupakan prasyarat bagi mencapai tujuan penyelidikan, di samping meminimakan kesalahan atau ralat. Perkara ini diingatkan, agar ciri penyelidikan dapat dipenuhi, antara ciri penyelidikan ialah sistematik ${ }^{44}$, iaitu ia melibatkan langkah-langkah yang teratur dan dilakukan peringkat demi peringkat.

Seterusnya, pemikiran reflektif yang berunsurkan memberi penekanan kepada urutan idea yang memberi kesan kepada perlakuan. Tujuan pemikiran reflektif ialah ${ }^{45}$, (1)bertindak, iaitu dalam bentuk paling ketika membuat keputusan, (2)menilai tindakan dan (3)penilaian kritikal, iaitu menilai secara keseluruhan bagi tujuan pembaikan. Individu yang mengaplikasikan pemikiran reflektif mampu menghadapi segala halangan sama ada peribadi

\footnotetext{
43 Mohd Nashuha Jamidin et. al. (1996), op. cit., h. 75.

44 Sidek Mohd Noah (2002), op. cit., h. 7.

45 Shahabudin Hashim et. al. (2003), op. cit., h. 76.
} 
atau profesional. Selain itu, dalam usaha mengimplementasikan pemikiran ini, individu perlu memiliki pemikiran terbuka, iaitu kesediaan menerima idea-idea orang lain, bersungguh-sungguh menyelesaikan sesuatu permasalahan dan yakin serta berani bertanggungjawab akibat daripada keputusan yang diambil ${ }^{46}$. Perkara paling penting di sini, dengan mengamalkan sikap terbuka dan positif, mampu membentuk pemikir reflektif yang berkesan dan berfungsi.

Seterusnya, elemen pemikiran metakognitif pula dilihat sebagi induk dalam aplikasi selektif pemikiran terbaik dalam penyelidikan. Metakognitif ialah berfikir berkenaan proses berfikir yang digunakan semasa memproses maklumat ${ }^{47}$. Dalam erti lain, kita mengurus pemikiran dan menentukan jenis-jenis kemahiran berfikir yang sedang digunakan. Strategi asas dalam proses metakognitif ialah ${ }^{48}$;

1. Mengaitkan maklumat baru dengan pengalaman/ pengetahuan sedia ada.

2. Memilih strategi berfikir secara sedar.

3. Merancang, memantau dan menilai proses berfikir.

Pemikiran metakognitif amat penting dalam rangka memastikan tujuan penyelidikan dapat dicapai secara optima. Secara holistiknya, kemahiran berfikir secara saintifik memberikan implikasi positif ke arah pembentukan minda yang proaktif dan reflektif. Pemikiran saintifik berupaya menyediakan seseorang dengan kebolehan-kebolehan berikut ${ }^{49}$ :

1. Berupaya menerokai fenomena baru dengan menggunakan pengetahuan sebelumnya.

2. Penanaman pemikiran kritis supaya dapatan yang kurang jelas atau boleh dicabar akan dapat dikenalpasti.

3. Berupaya memberi hipotesis atau ramalan ke atas sesuatu perkara berdasarkan maklumat sedia ada.

4. Menyedari bahawa pembuktian sesuatu jangkaan mestilah diperolehi melalui pemerhatian atau eksperimen.

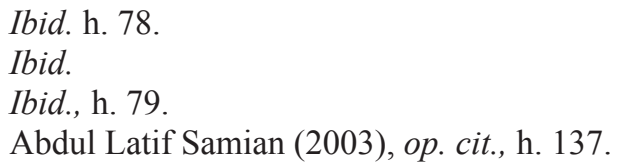


5. Berupaya untuk menguji dan menjalankan ujikaji hipotesis.

6. Berupaya menyelidikan pengaruh sesuatu angkubah terhadap angkubah lain.

7. Berupaya memahami perhubungan di antara angkubah dan pemahaman satu-satu konsep.

Penyelidikan ilmiah yang menggunakan pendekatan saintifik adalah bercirikan, sistematik, logik, empirik, reduktif dan replikasi serta terkawal. Seterusnya, penyelidikan saintifik melibatkan beberapa konsep asas seperti, ${ }^{50}$ pengukuran, kebolehpercayaan, kesahihan, kawalan, rambangan, keumuman dan unit analisis. Konsep-konsep tersebut penting dalam menentukan mutu dan tahap keyakinan terhadap penemuan dan kesimpulan suatu penyelidikan.

Namun selain aspek pemikiran, strategi berfikir dan konsepkonsep asas, elemen kedua terpenting yang mendasari penyelidikan saintifik ialah alat atau mekanisme yang digunakan dalam kaedah saintifik. Antara alat terpenting dalam menjayakan kaedah saintifik ialah andaian atau ramalan, ${ }^{51}$ kaedah statistik ${ }^{52}$ dan pengurusan grafik. $^{53}$ Jadual di bawah menunjukkan dengan jelas aspek fungsional dan peranan ketiga-tiga mekanisme tersebut dalam penyelidikan saintifik.

Alat

Ramalan

\section{Fungsi}

-mempengaruhi aktiviti penyelidikan secara konsisten

-asas kepada prosedur penyelidikan

-mempengaruhi kaedah penyelidikan

-memberi kesan terhadap interpretasi penemuan

50 Sulaiman Masri (2003), Kaedah Penyelidikan Dan Panduan Penulisan, Kuala Lumpur: Utusan Publications, h. 8.

51 Deobold P. Van Dalen (1993), op. cit., h. 16-17.

52 Abdul Latif Samian (2003), op. cit., h. 108-110.

53 Shahabudin Hashim (2003), op. cit., h. 83-86. 
Statistik

P engurusan Grafik -digunakan eksperimen yang memerlukan analisis ke atas perubahan kompleks -memproses data kuantitatif -memelihara keobjektifan data. -menjawab persoalan penyelidikan -menilai hipotesis sama ada diterima atau ditolak -melatih berfikir menggunakan alat-alat pengukuran

-mentafsir data

-merancang dan menyusun idea dengan cara yang teratur dan jelas

-mengawal dan memahami proses pemikiran sendiri

-menterjemah idea dalam bentuk nyata -menjadikan proses berfikir lebih sistematik -mengelakkan daripada berfikir secara terburuburu, sempit, kabur dan berkecamuk

(Jadual : Fungsi Andaian, Statistik \& Grafik Dalam Kaedah Saintifik)

Sehubungan itu, Ziauddin Sardar $^{54}$ membuat perbandingan corak sains Islam dan Barat daripada aspek falsafah, metodologi dan konseptual. Ternyata pendekatan falsafah sains Islam dan Barat wujud perbezaan ketara. Malah pendekatan falsafah bertemakan menyelidik dengan tujuan mencari kebenaran ${ }^{55}$ harus diintegrasikan dan disintesis dalam pengajian Syariah. Pendekatan ini memiliki sifat keilmuan, eksklusif dan terbuka. Kelebihan pendekatan ini untuk bidang pengajian Syariah boleh dirujuk kepada tiga perkara yang utama seperti berikut; ${ }^{56}$

i) Pencarian dan perumusan idea atau gagasan yang bersifat mendasar dalam berbagai persoalan.

54 Ziauddin Sardar (1992), Hujah Sains Islam, Abdul Latif Samian (terj.), Kuala Lumpur: DBP., hh.37-81.

55 Tuan Syed Mahussain Syed Ahmad Al-Idrus (2003), "Falsafah Sains Dan Teknologi Islam", dalam Ramli Awang (ed.), Falsafah Sains Dan Teknologi, Pahang: PTS Publications, h. 41.

56 Kamaruzzaman Bustaman Ahmad (2002), Islam Historis:Dinamika Studi Islam Di Indonesia, Yogyakarta: Galang Press, hh. 9-10. 
ii) Pengenalan dan mendalami persoalan serta isu-isu fundamental dapat membentuk cara berfikir yang kritis.

iii) Proses ini bakal membentuk mentaliti dan kaedah berfikir yang mengutamakan kebebasan intelektual dan wujud toleransi fiqh serta menafikan fanatisme mazhab.

Paradigma lain, namun masih dalam skop yang sama iaitu, peranan pemikiran saintifik dalam pengajian Syariah, khususnya pembinaan hukum Islam semasa. Pemikiran saintifik merujuk kepada dua komponen asas, iaitu falsafah dan kaedah berfikir yang digunakan oleh ahli sains di dalam aktiviti- aktiviti yang dilaksanakan. Aspek falsafah, ahli sains menyoal dan berfikir tentang kebenaran dan objektif sains. Manakala dari sudut kaedah berfikir pula, pemikiran saintifik bermaksud kaedah berfikir yang diamalkan oleh ahli sains.

Sehubungan itu, kaedah berfikir ini mempunyai hubungkait secara langsung dengan matlamat sains dan memberi implikasi besar dalam memahami dan memperkembangkan sains sebagai satu bidang ilmu yang dinamik. Sebenarnya elemen pemikiran saintifik seperti sistematik, formal dan objektif ternyata wujud dalam Islam bagi memudahkan manusia memahami dan menjalani kehidupan harian dengan lebih teratur. ${ }^{57}$ Realitinya, umat Islam tidak dihalang oleh agamanya untuk berfikir secara saintifik melalui kaedah yang digunakan oleh pemikir Barat, selagi ianya tidak mempunyai kontradiksi dengan agama.

Penguasaan serta aplikasi pemikiran saintifik secara realitinya adalah merupakan tuntutan Islam dan akan menentukan ketamadunan sesuatu bangsa terutama masyarakat Islam itu sendiri. Ilmu itu juga yang akhirnya mampu memartabatkan maruah agama Islam pada pandangan agama- agama lain. Pembangunan dan pelaksanaan Syariat Islamiah sebagai visi dan misi unggul, secara praktiknya memerlukan projeksi minda yang bersifat ekploratif, meneroka, menyelidik dan mempelajari ilmu Syariah kemudiannya diproduksikan manfaatnya secara holistik. Sesetengah data sains dapat digunakan untuk memahami teks al-

57 Abdul Halim El-Muhammady (1993), Perkembangan Undangundang Islam Dari Zaman Rasulullah S.A.W. Hingga Zaman Penjajahan Barat, Kuala Lumpur: ABIM, h. 2. 
Quran dengan lebih mendalam. ${ }^{58}$ Tidak dinafikan juga, penemuan sains telah menzahirkan keagungan wahyu dan ilmu sains dan teknologi dieksploitasikan sebagai alat berfikir tentang kewujudan Allah. ${ }^{59}$

\section{APLIKASI ELEMEN PEMIKIRAN SAINTIFIK DALAM PENGAJIAN SYARIAH : PERSPEKTIF METODOLOGI}

Apa yang jelasnya, pada zaman keunggulan tamadun Islam, umat Islam telah mempraktikkan budaya ilmu yang tinggi. ${ }^{60} \mathrm{Di}$ antara faktor kecemerlangan budaya ilmu ini ialah bersikap terbuka dan selektif terhadap jenis ilmu dan metodologi pengajiannya di samping proses Islamisasi terkawal aspek epistemologi ilmu terbabit. ${ }^{61}$ Faktor berikutnya ialah pemikiran analitikal kritis yang digarapkan terhadap ilmu tanpa sifat fanatik kepada seseorang guru. Kepentingan utama di sini, warisan fiqh silam perlu dikaji dan dinilai semula keberkesanannya berhadapan dengan tuntutan pasaran semasa dan arus pemodenan Malaysia.

Berasaskan kesedaran ini, usaha rekonstruktif pengajian Syariah patut dilakukan melalui pendekatan aplikasi keilmuan moden khususnya sains demi memastikan kerelevenan warisan silam ini. Rasionalnya, mana-mana institusi besar dan berpengaruh perlu memiliki identiti sendiri yang mantap. Pengajian Syariah di Malaysia harus mempunyai metodologi yang berotoriti sebelum bergerak lebih jauh. Merujuk kepada perkara di atas dan situasi semasa, kita harus meletakkan beberapa asas penting dalam membangunkan sistem pengajian Syariah sedia ada.

\footnotetext{
58 A. Rahman Omar (1990), "Fizik: Perkembangannya Dalam Tamadun Islam", dalam Baharudin Yatim \& Sulaiman Noordin (eds. ), Sains Menurut Perspektif Islam, Bangi: UKM, hh. 18- 19.

59 Sulaiman Noordin (1990), "Biologi Daripada Perspektif Islam", dalam Baharudin Yatim \& Sulaiman Noordin, Ibid., hh. 24- 25.

60 Shaharir Mohamad Zain (2005), "Sains Dan Teknologi Melayu Sebelum Dikuasai Penjajah Dari Eropah", dalam Rogayah A. Hamid \& Mariam Salim (eds.), Kepustakaan Ilmu Tradisional, Kuala Lumpur: DBP.

61 Ibid.
} 
Oleh kerana pengajian Syariah bersifat dinamis, skop dan metodologi pengajiannya juga harus berkembang seiring dengan keperluan masyarakat dan pengajian itu sendiri. Fokus kepada silibus umum pengajian Syariah adalah terdiri daripada wahyu dan hasil ijtihad fuqaha. Warisan ilmu dikodifikasikan dalam pelbagai bentuk penulisan termasuk yang dikenali sebagai kitab-kitab fiqh. Umumnya, warisan ini adalah merupakan hasil kefahaman para fuqaha terhadap kehendak syariah yang bercirikan wahyu. Kefahaman berasaskan pemikiran fuqaha adalah sesuatu yang sentiasa berkembang mengikut keadaan, kemampuan intelektual dan realiti hidup.

Hakikatnya, tidak ada jalan mudah untuk menjadikan pengajian Syariah lebih berdaya maju dan multi-fungsional pada era kini. Metodologi pengajian yang perlu dilaksanakan secara umumnya ialah pertama; menerapkan semua elemen ilmu yang berbentuk warisan fiqh dalam silibus pengajian, kedua; meneliti dan mengimbas langsung isu-isu semasa dan ketiga; usaha sintesis segala bentuk metodologi pengajian sains secara selektif positif. Natijahnya, melalui metodologi inilah diharapkan agar prinsipprinsip syariah yang terkandung dalam al-Quran dan al-Sunnah akan diimplementasikan secara integratif dengan nilai-nilai intelektual semasa.

Bagi merealisasikan wacana ini, perlu diwujudkan pola pemikiran secara paralel. ${ }^{62}$ Ini bertujuan untuk membezakan antara prinsip Syariah sebagai asas pemikiran dalam menyelesaikan masalah hukum dan warisan fiqh yang merupakan hasil asimilasi antara prinsip Syariah dengan intelektual tertentu. Pendekatan ini, harus juga diproduksikan secara serentak dengan elemen pemikiran kritis dan kreatif. Kedua-dua elemen pemikiran digabungkan secara bersama bagi menilai kesimpulan baru seterusnya membentuk reka bentuk konsep yang lebih holistik. Selain itu, ianya bakal membentuk mentaliti sarjana yang mengutamakan kebebasan intelektual.

62 Ainon Mohd. Abdullah Hassan (1997), Memahami Pemikiran Lateral, Kuala Lumpur: Utusan Publications, hh. 48-49. Pemikiran paralel atau berfikir secara selari dengan membuat pemilihan idea berdasarkan kelebihan yang wujud antara idea tersenarai. 
Perkara yang menjadi teras bagi pengajian Syariah $^{63}$ adalah untuk membantu pelajar bagi mengetahui, memahami, mengamalkan, menghayati (analisis, sintesis, penilaian, hidup) dan membudayakan (pengembangan) konsep, proses, prinsip, kemahiran, prosedur, peraturan, kepercayaan, nilai, akhlak dan adab. Kekuatan pengajian Syariah adalah satu konsep yang boleh digunakan untuk menandakan beberapa kecekapan dan kebolehan yang perlu dibina oleh setiap pelajar pengajian Syariah. Sebagai tambahan, beberapa ciri pengetahuan yang dimiliki oleh pelajar boleh dikategorikan seperti berikut; ${ }^{64}$

1) Berasaskan pembinaan oleh pemikiran pelajar sendiri dan bukan ditemui olehnya dalam persekitaran fizikal. Pengetahuan berkaitan ilmu syariah melalui asas ini adalah tidak sempurna.

2) Hasil daripada aktiviti yang melibatkan pengetahuan sedia ada atau daripada keperluan dalam kehidupan seharian.

Kedua-dua ciri pengetahuan di atas selepas pembentukannya, boleh membabitkan salah faham, salah tafsir dan terbuka kepada pemantapan dan pemurniaan. Pemikiran pelajar adalah sebuah penjana untuk diaktif. Kaedah percambahan fikiran boleh digunakan untuk menjana seberapa banyak strategi pemikiran yang sesuai diaplikasi dalam metodologi pengajian Syariah. Perkara ini penting bagi mengisi ruang pemantapan dan pemurniaan pemikiran pelajar.

Dalam pada itu, penerapan elemen pemikiran reflektif amat releven dikoordinasikan dalam metodologi pengajian Syariah berasaskan isu pembinaan pengetahuan pelajar seperti di atas. Pemikiran ini mampu memotivasikan pelajar agar berfikir secara urutan idea, cepat membuat keputusan, penilaian kritikal dan menggalakkan berfikir secara terbuka. Kemampuan dan kemahiran ini berperanan dalam mereka bentuk penyelesaian masalah

63 Idea ini adaptasi penulis terhadap strategi pendidikan Islam di Malaysia yang dibincangkan oleh beberapa orang sarjana pendidikan negara dan perbincangan berkaitan dimuatkan dalam Nik Aziz Nik $\mathrm{Pa}$ (ed.) (2007), Pendidikan Islam \& Bahasa Arab Berteraskan Islam Hadhari, Putrajaya: Yayasan Islam Hadhari.

64 Nik Aziz Nik Pa (2007), Isu-Isu Kritikal Dalam Pendidikan Islam, Putrajaya: Yayasan Islam Hadhari, hh. 4-5. 
berdaya maju. Di sinilah terletaknya peranan fiqh jika dilihat kepada silibus umum pengajian Syariah. Ini adalah kerana Syariah Islam menyediakan prinsip umum politik, ekonomi, sosial dan sebagainya. Sehubungan itu, menjadi tanggungjawab para sarjana Syariah menjawab persoalan masakini dengan menggarapkan prinsip, kaedah dan sistem warisan fiqh di samping usaha analisis elemen budaya, sosial dan implikasi sains dan teknologi.

Adalah tidak wajar menafikan peranan sumber warisan kerana tanpa sumber tersebut ilmuan zaman kini tidak akan memiliki apaapa. Analisis komparatif perlu diterapkan secara sistematik dan berdasarkan kaedah induktif. Pendekatan ini memberi peluang kepada pelajar untuk berfikir berdasarkan fakta dan hukum umum yang diketahui. Selain itu, pendekatan ini berkait rapat dengan pembentukan budaya inkuiri, iaitu pelajar tidak secara langsung diberikan jawapan terhadap sesuatu masalah tetapi dibimbing untuk memperolehi jawapan. Pelajar dilatih untuk berfikir dan membuat keputusan atas daya usaha sendiri. Ilmu yang diperolehi lebih bermakna, di samping membentuk kemahiran mencari maklumat selain daripada merujuk buku teks mereka.

Secara ringkasnya, dapat dirumuskan di sini bahawa aplikasi elemen pemikiran saintifik dalam metodologi pengajian Syariah perlu diberikan penekanan kepada aspek penjanaan pemikiran pelajar. Pendekatan ini dapat melahirkan pelajar yang mempunyai kemahiran berfikir secara rasional, teliti dan objektif. Selain itu juga, pelajar turut dibekalkan dengan daya rumus dan analisis yang akan meningkatkan kemampuan ijtihad. Kemampuan ijtihad ${ }^{65}$ pelajar sewajarnya berteraskan metodologi istinbāt dan istidlāl dengan merujuk kepada sumber warisan dan moden yang berautoritatif. Pelajar seharusnya mempunyai kemahiran saintifik hasil aplikasi pemikiran saintifik. Kemahiran ini antara lainnya dapat meningkatkan upaya meneroka fenomena baru berlandaskan pengetahuan sedia ada. Di samping menguasai keupayaan menguji, menyelidik dan memahami perkaitan yang wujud antara teori, konsep dan prinsip umum terkandung dalam pengajian Syariah.

65 Shukeri Mohamad (2000), “Asas-asas Pembentukan Fiqh Malaysia: Satu Saranan", dalam Paizah Ismail \& Ridzwan (eds.), Fiqh Malaysia: Ke Arah Pembinaan Fiqh Tempatan Yang Terkini, Kuala Lumpur: APIUM, h. 48. 


\section{APLIKASI ELEMEN PEMIKIRAN SAINTIFIK DALAM PENGAJIAN SYARIAH: PERSPEKTIF PEDAGOGI}

Pada umumnya, matlamat utama dalam pelaksanaan sistem pendidikan Islam adalah untuk memberikan kemahiran, pengetahuan dan membangunkan insan yang bertakwa kepada Allah S.W.T. Tugas pendidik khususnya pengajian Islam kini lebih tertumpu kepada pembangunan intelektual para sarjana dengan tujuan utama untuk memajukan masyarakat Islam yang menjadi teras kepada masyarakat di Malaysia. Oleh itu, tugas pendidik dalam pengajian Syariah khususnya tidak seharusnya sekadar menjurus kepada persoalan pemindahan maklumat tetapi juga berkaitan dengan aspek pembentukan para sarjana Syariah yang memiliki nilai intelektual semasa.

Dalam perbincangan di sini, pedagogi pengajian Syariah merujuk kepada kaedah pengajaran dan pembelajaran yang diamalkan dalam sistem pengajian Syariah. Pengajaran adalah kaedah yang digunakan oleh pendidik untuk menyampaikan pelajaran atau ilmu pengetahuan kepada para pelajar. Pengajaran merupakan satu proses yang mempunyai matlamat dan tujuan. Sesuatu proses pengajaran yang dikatakan berjaya sekiranya matlamat dan tujuan tercapai. ${ }^{66}$ Selain itu menurut Ab. Halim Tamuri:

"Pengajaran merupakan suatu seni kerana dalam proses pengajaran itu seseorang guru perlu kreatif. Guru yang kreatif akan menjadikan pengajaran lebih menarik dan berkesan". ${ }^{67}$

Kaedah pengajaran dalam pengajian Syariah perlu diajar dengan lebih menarik dengan menjadikan pengajaran lebih berkaitan dengan permasalahan semasa dan menyepadukan unsur kemahiran berfikir dalam proses pengajaran dan pembelajaran (P\&P). Kaedah

\footnotetext{
66 Ab. Halim Tamuri (2007), “Amalan Pengajaran Guru Pendidikan Islam Dalam Membangunkan Masyarakat Islam Hadhari”, dalam Nik Azis Nik Pa (ed.), Pendidikan Islam \& Bahasa Arab Berteraskan Pendekatan Islam Hadhari, Putrajaya: Yayasan Islam Hadhari, h. 178.

67 Ibid.
} 
dan teknik yang disarankan ialah kaedah penyelesaian masalah, syarahan, hafalan, demonstrasi dan perbincangan.

Mengikut analisis yang dibuat oleh Dr. Wan Salim Wan Mohd Daud ${ }^{68}$ pusat-pusat pengajian tinggi yang terlibat dengan pengajian Islam di Malaysia adalah agak ketinggalan dalam realisasikan P\&P berbanding dengan pengajian lain. $\mathrm{P} \& \mathrm{P}$ di pusat pengajian tinggi masih mengikut cara pendidikan tradisional yang diwarisi zaman silam. Sepatutnya pengajian Islam khusus pengajian Syariah tidak hanya berperanan sebagi pewaris keilmuan zaman silam, malah mestilah juga mampu membina budaya umat bercirikan integratif dengan realiti semasa. Implikasi negatif ${ }^{69}$ daripada pelaksanaan P\&P secara tradisional ini ialah bakal melahirkan pemimpin yang lemah, berfikiran sempit, hanya tahu menghafal tetapi tidak pandai berfikir. Kesinambungan itu juga, sarjana Syariah yang bakal dilahirkan hanya akan bersifat pasif menerima pandangan tanpa bersikap kritikal, suka bertaqlid dan tidak mampu berijtihad serta tidak kreatif tanpa mempunyai daya reka dan daya cipta.

Pada peringkat asasnya, ciri utama pedagogi berteraskan aplikasi elemen saintifik adalah bukan hanya memberi maklumat dan informasi yang terkandung dalam perbendaharaan fiqh. Bahkan, melalui pendekatan membentuk kemahiran berfikir yang dapat melahirkan pelajar yang berfikiran kritikal dan kreatif. Kesannya pelajar mempunyai kemampuan berfikir secara ilmiah dan praktikal ${ }^{70}$ serta berjaya melenyapkan sindrom beku, jumud dan taqlid. Sindrom atau gejala tersebut amat dibimbangi oleh sarjana Islam ${ }^{71}$ kerana ianya bakal memberi impak kepada penghayatan sebenar terhadap konsep dan prinsip syariah yang syumul.

Begitu banyak kemahiran berfikir yang boleh diterapkan dalam P\&P pengajian Syariah. Peranan pendidik dalam hal ini adalah sebagai pemudah cara dan pembimbing kepada pelajar.

68 Wan Salim Wan Mohd Daud (1990), "Pendidikan Islam Di Pusatpusat Pengajian Tinggi: Masalah Dan Penyelesaian", Jurnal Pendidikan Islam, jld. 3, bil. 2, hh. 1-12.

69 Ibid.

70 Edward de Bono (2001), op.cit., hh. 1-10.

71 'Abd al-Qādir 'Audah (1951), Al-Islām Baina Jahli Abnāihi Wa 'Ajzi 'Ulamā'ihi, Kaherah, h. 29. 
Pembudayaan pemikiran analogi dan abduktif boleh diaplikasikan dalam P\&P untuk memberikan kefahaman tentang konsep bagi menjalankan penganalisaan teori yang rumit. Elemen ini penting diterapkan dalam pengajaran tentang konsep mașālih al-mursalah dan kaedah-kaedah maqāsșid yang memerlukan proses penilaian dan bersifat kontektual. $^{72}$ Seterusnya disintesiskan dengan instrumen al-qiyas bagi menemukan hasil akademik yang bersifat semasa. Pelajar sewajarnya didedahkan tentang pandangan global (global outlook) agar mereka terbiasa dengan pemikiran global. Perkara ini amat realistik jika melihat prinsip syariah antara lainnya terkandung unsur universal ('alamiyyah). Kaedah kemahiran saintifik yang diterapkan dapat membantu pendidik dalam merangsang dan menggalakkan pelajar bagi mengikuti pelajaran secara lebih aktif khususnya dalam aktiviti berdiskusi.

Kaedah pedagogi yang disarankan dalam pengajian Syariah sebenarkan tidak banyak berbeza dengan kaedah yang diaplikasikan dalam pengajian sains. Ini mungkin disebabkan oleh ilmu sains itu sendiri adalah sebahagian daripada ilmu agama. Sebagai contoh kedua-dua bidang pengajian ini menyarankan pengintegrasian kemahiran berfikir. Selain kaedah inkuiri amat penting diterapkan dalam pengajian Syariah sebagaimana pengajian sains, kaedah demonstrasi juga boleh diterapkan dalam P\&P pengajian Syariah. Alat bantu pemikiran seperti penggunaan statistik dan pengurusan grafik amat sesuai diaplikasi dalam P\&P pengajian.

Demonstrasi melalui penggunaan statistik dan grafik dapat menimbulkan minat dan menambahkan lagi kefahaman pelajar terhadap sesuatu subjek yang diajar. Kaedah talaqqī dalam P\&P atau berasaskan teks atau kitab semata-mata bakal mewujudkan suasana pembelajaran yang kaku dan membosankan. Pengajian Syariah merujuk kepada fiqh adalah berasaskan bentuk pengajian amali, maka amalan P\&P seharusnya bersifat praktikal dan bukan teoretikal.

Kemahiran P\&P adalah penting bagi menjalankan tugas sebagai pendidik yang berkesan. Antara kemahiran mengajar yang perlu dikuasai ialah kemahiran memulakan pengajaran melalui kaedah mengemukakan persoalan, menggunakan contoh-contoh dan

72 Rosli Mokhtar (2007), Pengenalan Ilmu Maqasid, Selangor: Karya Bestari, hh. 89-114. 
pemaparan isu melalui imbasan persekitaran. Kreativiti pendidik dalam melaksanakan tugas $\mathrm{P} \& \mathrm{P}$ adalah penting bagi suasana pembelajaran yang kondusif dan efektif. Isu-isu hukum semasa yang berorientasikan perkembangan sains dan teknologi wajar dikemukakan secara sistematik.

Elemen sistematik $^{73}$ dalam pedagogi pengajian Syariah berfungsi dalam memastikan pengajaran dan pengkajian dapat mencapai tujuan dan meminimumkan ralat. Penerapan boleh direalisasikan dalam perbincangan metodologi hukum yang berasaskan talfiq, takhayyur dan tarjīh. Perbincangan atau diskusi perlu diakhiri dengan aktiviti peneguhan dan pengukuhan. Melalui kaedah sistematik tersebut, pelajar-pelajar akan terangsang untuk turut sama terlibat dalam aktiviti P\&P secara aktif. Komunikasi pelbagai hala akan terhasil daripada proses yang menjadikan proses P\&P lebih menarik dan berkesan.

Sebagai konklusi sederhana di sini, pedagogi pengajian Syariah harus dimantapkan seiring dengan arus pemodenan semasa. Amalan P\&P yang berjaya dan berkesan mampu mengubah persepsi dan perspektif negatif pelajar terhadap pengajian itu sendiri. Jika sebelumnya pengajian Syariah dilihat sebagai pengajian yang bercirikan statik dan dogmatik, malah lebih ironis belajar ilmu Syariah dilabelkan sebagai belajar ilmu sejarah. Pemanfaatan elemen pemikiran saintifik dalam pedagogi pengajian Syariah dapat melahirkan pelajar yang berdaya saing serta berinovasi. Melalui pemikiran yang inovatif dapat mencetuskan idea baru dan berkemampuan mereka cipta kaedah penyelesaian masalah yang idealistik dan realistik. Segala permasalahan dapat dirungkai dengan mudah apabila manusia mengembangkan cara berfikiran dinamis dan sanggup menerima perubahan untuk lebih maju.

\section{KESIMPULAN}

Usaha aplikasi elemen pemikiran saintifik dalam pengajian Syariah semasa boleh dianggap sebagai keperluan yang amat mendesak, lebih-lebih lagi pada era globalisasi amat memerlukan sikap keprihatinan dan pro-aktif di kalangan fuqaha Islam untuk

73 Ibid. 
menawarkan formula penyelesaian masalah Islam terhadap pelbagai persoalan kehidupan yang timbul dalam masyarakat.

Pandangan prejudis dan stereotaip terhadap usaha aplikasi elemen saintifik dan pengajian Syariah harus dielakkan. Mungkin perbezaan yang perlu kita awasi ialah persoalan falsafah yang mendasari pemikiran yang dikatakan saintifik itu. Pemikiran saintifik yang berasaskan falsafah mekanisme Descartes, misalnya $^{74}$, menolak peranan Tuhan dalam memahami kejadian alam, atau kebenaran hanya boleh diterima jika ianya boleh diuji dan disahkan oleh rasionaliti akal semata- mata.

Rasionalnya ialah kebangkitan kesedaran di kalangan sarjana Islam tentang peri pentingnya dilakukan penerapan saintifik moden yang lebih berjiwa Islam ke dalam sistem pengajian Syariah moden. Hal ini perlu dilakukan sebagai langkah pro-aktif untuk membangun kerangka saintifik Islam yang lebih bersifat Islamik dan memenuhi keperluan zaman moden. Selepas Malaysia mencapai status kemerdekaan, di era 1960an-1980an telah timbul beberapa usaha untuk membangunkan masyarakat Malaysia ke arah status yang lebih baik berbanding dengan zaman penjajahan kuasa Barat.

Di samping itu kita tidak menafikan bahawa sains dan pemikirannya perlu bagi pembangunan intelektualisme Islam kontemporari. Elemen kaedah pemikiran saintifik seperti sistematik, logikal, analogikal, objektif, formal, penggunaan statistik dan matematik yang telah sedia diadaptasikan dalam tradisi keintelektualan Islam, harus diteruskan secara efektif bagi memantapkan pembinaan pemikiran hukum Islam. Dalam pada itu, pemikiran saintifik Barat perlu diasimilasi dan diislamisasi secara kondusif dan selektif demi pembangunan hukum Islam yang bersifat kontemporari dan dinamik.

Di sini, penulis bukan bermaksud bahawa keterikatan pengajian Syariah terhadap tradisi silam dan ketetapan hukum yang berasaskan metodologi kajian ilmiah sedia ada menghalang kemajuan dan pemodenan masyarakat Islam. Tetapi apa yang dikehendaki daripada usaha aplikasi pendekatan baru adalah berteraskan realisasi maslahah sebenar fokus pengembangan

74 Abdul Latif Samian et al. (2003), op.cit., h. 132. 
dinamisme pengajian Syariah itu sendiri. Seperti mana pendapat Wan Mohd Nor, ${ }^{75}$ kelemahan umat Islam dalam peradaban selama beberapa kurun ini bukanlah disebabkan kelemahan sistem epistemologi dan metod pentafsiran sumber-sumber agama. Umat Islam mundur kerana menyimpang daripada mempraktikkan sistem pengajian Islam seperti generasi terdahulu.

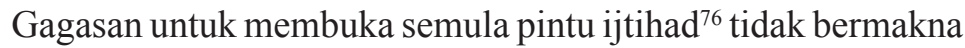
apa-apa sekiranya infrastruktur keilmuan, khususnya institusiinstitusi pengajian yang menawarkan pengajian Syariah tidak mantapkan, terutamanya daripada segi epistemologi, metodologi dan pedagogi pengajiannya. Selain itu, langkah pro-aktif boleh diambil dengan menyediakan pusat penyelidikan atau makmal kajian intensif di pusat- pusat pengajian Syariah. Realitinya, dalam catatan sejarah ketamadunan sains Islam silam, ${ }^{77}$ observatori atau pusat penyelidikan dan lebih dikenali sebagai cerapan astronomi merupakan institusi penyelidikan yang disepakati oleh sejarawan sains sebagai tempat bermula tradisi sains Islam.

Pengembangan pengajian Syariah harus diperluaskan skopnya meliputi kerja- kerja lapangan dan kajian makmal, bukan sekadar berbentuk teori, falsafah, kepustakaan dan talaqi $^{78}$ seperti sedia ada semata-mata. Sesuai dengan keperluan semasa dan keperluan memperlengkapkan mahasiswa sebagai bakal mujtahid berwibawa di era kini, adalah dicadangkan dimasukkan beberapa kursus pengajian sains bagi melahirkan generasi fuqaha yang intelek dan integratif penguasaan ilmunya.

Di sini, dapat kita katakan bahawa usaha mewujudkan lulusan pengajian Syariah yang serba boleh dan mampu memberi sumbangan yang bermakna kepada masyarakat samada di peringkat tempatan ataupun antarabangsa bukanlah suatu harapan

75 Wan Mohd Nor (2004), "Kaji Ide-ide Rahman Secara Kritis Dan Jujur" ISLAMIKA, Agustus, h. 57.

76 Amir Husin Mohd Nor (2000), "Penutupan Pintu Ijtihad: Satu Kajian Semula" Jurnal Syariah, 8:1, Januari, Kuala Lumpur: APIUM, hh. 43-45.

77 Hairudin Harun (1992), Kepintaran Buatan: Komputer Atau Falsafah?, Kuala Lumpur:DBP, h. 79.

78 Abdullah Ishak (1992), Islam Di Nusantara (khususnya di Tanah Melayu), Kuala Lumpur: BAHEIS, hh. 166- 168. 
yang mustahil. Pandangan ini tidak dibuat secara sewenangwenangnya, tetapi telah dibuktikan dengan fakta sejarah yang menunjukkan sifat serba boleh (versatile) yang dimiliki oleh lulusan ini, yang secara terang-terangan telah memberi impak yang cukup besar di dalam pembentukan tamadun intelektual dan material masyarakat Islam. Fakta dan peristiwa sejarah ini sepatutnya tidak hanya dibanggakan secara kosong, tetapi perlu disertakan dengan pelbagai pelan bertindak bagi memastikan lulusan pengajian Syariah ini tetap releven untuk realiti semasa. 
Jurnal Fiqh, No. 7 (2010) 1-28 